\title{
It's Not Just the Money: Why Consumers Do Not Purchase Pharmacist-Provided Services
}

\author{
Patricia R. Freeman1,2, Mikael Jones1,2, Karen Blumenschein"1,2,3 \\ ${ }^{1}$ Department of Pharmacy Practice and Science, University of Kentucky College of Pharmacy, Lexington, USA \\ ${ }^{2}$ Center for the Advancement of Pharmacy Practice, University of Kentucky College of Pharmacy, Lexington, \\ USA \\ ${ }^{3}$ Martin School of Public Policy and Administration, University of Kentucky, Lexington, USA \\ Email: kblum1@email.uky.edu
}

Received 10 April 2014; revised 12 May 2014; accepted 4 June 2014

Copyright (C) 2014 by authors and Scientific Research Publishing Inc.

This work is licensed under the Creative Commons Attribution International License (CC BY). http://creativecommons.org/licenses/by/4.0/

(c) (i) Open Access

\begin{abstract}
The reimbursement model for pharmaceutical care remains a barrier to successful widespread implementation of pharmacist-provided services. In some instances, community pharmacists have been successful in obtaining direct compensation for services from patients; however, evidence suggests that lack of patient demand for pharmacist-services may ultimately undermine the campaign for widespread third-party payment. The purpose of this study is to conduct a secondary analysis of data indicating consumer/patients' rationale for not purchasing pharmacist-provided disease management services when offered the opportunity to do so in community pharmacies. Our review of the data indicates that while financial concerns are clearly important in consumer demand for pharmacist-provided services, other considerations exist. The consumer/patient belief that pharmacist-provided services are duplicative or that these services are not needed are significant barriers to overcome. Intensive education and marketing campaigns are needed to sway consumer opinion on the value of pharmacist-provided services.
\end{abstract}

\section{Keywords}

Pharmacist-Provided Services, Pharmaceutical Care, Compensation

\section{Introduction}

Significant changes have occurred in community pharmacy practice over the past two decades. With the advent of third-party payers for pharmacy services, reimbursement for dispensing services and profitability have decreased significantly [1] [2], with most plans reimbursing at a rate less than the average cost of dispensing [3]. 
Faced with diminished dispensing returns, community pharmacists have altered their business models to include compounding and integrated pharmaceutical care practices such as health and wellness screenings, medication therapy management (MTM), chronic disease management and immunization services [4] [5]. During this time, a multitude of studies have documented the contribution pharmacists can make in lowering total healthcare costs and improving health outcomes [6]. However, the reimbursement model for pharmacist-provided professional services remains a significant barrier to successful implementation of these advanced pharmacy services both in the US and abroad [7]-[10].

A pre-requisite for the development of an adequate reimbursement model for pharmacist-provided services is patient, provider and payer demand for such services. Third-party payers have recognized the value of pharmacist-provided immunizations and reimbursement of these services today is commonplace [11]. Medicare, Medicaid and all major private insurance plans reimburse for pharmacist-administered immunizations, including influenza, pneumococcal and zoster vaccine, although billing processes may vary between plans [11]. Since passage and implementation of the Medicare Prescription Drug, Improvement, and Modernization Act of 2003, MTM services are mandated under Medicare Part D for high risk patients meeting specific criteria and all Part D Drug Plans reimburse qualified pharmacists for providing these services [12]. Reimbursement for disease management services, however, has proved more challenging for pharmacists.

Disease-management programs are typically developed around diseases that are associated with significant morbidity, mortality, and increased healthcare costs, such as diabetes, hypertension, dyslipidemia, and asthma, or those that require extensive monitoring to avoid negative outcomes such as anticoagulation monitoring in the setting of atrial fibrillation. Pharmacists can potentially obtain payment for disease management from Medicare, Medicaid, private third-party payers, or patients [13]. However, payment is limited by the fact that pharmacists are not recognized as healthcare providers by CMS and other payers. Thus, while a few have been successful in securing payment for pharmacist-provided disease management services, compensation from third-party payer groups is too inconsistent in most cases to ensure the complete financial support of a disease management service [14]. In some instances, community pharmacists have been successful in obtaining direct compensation for disease management and other cognitive services from patients [15] [16]. However, evidence suggests that lack of patient demand for disease management and education programs from the pharmacist may ultimately undermine the campaign for third-party payment for these pharmacist-provided services [7]. One additional challenge pharmacists face when obtaining payment from patients is establishing a price for the disease management service that is sufficient to support the services, yet is perceived as a good value by the patient.

Contingent valuation, or willingness to pay, is a survey method that elicits the amount of money a consumer is hypothetically willing to pay for a good, service, or change in health status [17]. Contingent valuation studies can be useful in determining consumer demand for pharmacist-provided services, including MTM and disease management programs [18]-[20]. This information can be utilized to assess the feasibility of establishing a planned disease management program, derive a charge for the program, and possibly even to develop a copayment pricing scheme for the program [19].

Willingness to pay studies typically do not provide information on why patients are not willing to purchase the item being valued. The rationale for a patient's un-willingness to purchase a pharmacist-provided service could be very useful in determining the feasibility of disease management program implementation, identifying real or perceived access barriers for patients, or characterizing the patient's perceptions of the disease management service. Ultimately, determining the reasons why patients are unwilling to purchase pharmacist-provided services may prevent the implementation of services that might be grossly underutilized and cost-ineffective. The purpose of the current study is to analyze the rationale provided by patients who chose NOT to purchase pharmacist-provided disease management services when offered the opportunity to do so in community pharmacies.

\section{Methods}

This study used existing data regarding consumer rationale for not purchasing pharmacist-provided disease management services when offered the opportunity to do so. The data were obtained from three previously conducted willingness to pay surveys [21]-[23]. These three studies were carefully constructed and made every attempt to conform to guidelines recommended for conducting contingent valuation surveys [17] [24]. Each study examined "hypothetical" willingness to pay (i.e., no payment was required from the consumer/patient and no 
service was provided) versus "real" willingness to pay (i.e., payment for the service was required from those wishing to receive the service) for a pharmacist-provided disease management service. The three diseases studied were asthma, dyslipidemia, and diabetes.

Detailed descriptions of the study design are published elsewhere [21]-[23]. Briefly, in each study, a pharmacist-provided disease management service was offered for a three-month period to the consumer/patient. Subjects were recruited from independent community pharmacies located throughout Kentucky. Pharmacies were randomized to either the hypothetical or real group, such that consumer/patients at the real pharmacies received a real offer to purchase the service (i.e., they actually had the opportunity to purchase the disease management service) and consumer/patients at the hypothetical pharmacies received a hypothetical offer to purchase the service (i.e., they did not have the opportunity to actually purchase the disease management service). Consumer/ patients who received the real offer and said "yes" to the purchase question paid for the service and were then entitled to receive the pharmacist-provided disease management service for three subsequent months.

Consumer/patients declining the offer to purchase the disease management service were asked to provide a written reason stating why they did not purchase the service. These motivation responses are recommended in contingent valuation surveys to identify potential "protest" responses, a form of strategic bias where the respondent makes an unreasonable response to the contingent valuation question [17] [24]. In addition to identifying protest responses, the motivation responses provide important insight into what consumer/patients think about pharmacist-provided disease management services. Motivation responses were obtained from all consumer/patients who received hypothetical offers to purchase the services, and from consumer/patients who received the real offer to purchase the dyslipidemia and diabetes services.

Each motivation response was reviewed by a panel consisting of one investigator (KB) and two pharmacy students in their final year of the Doctor of Pharmacy program. Motivation responses were assigned to one of the following five categories: insufficient funds; already obtain the service from some other healthcare professional; no need for the service described; no time to participate or no transportation available; and miscellaneous. The miscellaneous category was used for motivation responses that did not readily fit into one of the other four categories. Each panel member independently reviewed all of the motivation responses and assigned them to a category. The panel then met and formed a consensus on the assignment of motivation responses to individual categories. In some instances, respondents provided more than one reason, or provided reasons that could be included in more than one category. If the panel could not reach a consensus, the motivation response was assigned to each category identified by panel members. There were no a-priori hypotheses. Results are described descriptively.

\section{Results}

A total of 554 consumer/patients were offered the opportunity to purchase one of the three disease management services; 376 (67.9\%) declined to pay for the service they were offered. Motivation data were available from 297 respondents (motivation was not collected from consumer/patients in the real group for the asthma study). Ten subjects provided two reasons for declining the offer to purchase the service. Table 1 provides a summary of demographic information for all subjects. Those participating in the asthma study were younger, and more likely to be female with lower income. Subjects participating in the lipid study had more years of education on average.

Table 2 summarizes the reasons cited by subjects for not purchasing the disease management services. Lack of financial resources was the most common reason to decline both the diabetes $(40.1 \%)$ and asthma management programs (50\%), while the perception that another healthcare provider already provided the service was the most common reason to decline the lipid management program (51.8\%). When combining responses from all three studies, overall, lack of financial resources was the most common reason cited (37.5\%), followed by the perception that the service was already being provided by some other healthcare provider (30.3\%) and the perception that the program is not needed (17.4\%). Lack of time or transportation was cited as the motivation for declining the offer to purchase in less than $10 \%$ of all respondents.

\section{Discussion}

This review of data from 297 consumers who declined the offer to purchase pharmacist-provided disease management service indicates that financial considerations impact purchase decisions. The second most common 
Table 1. Subject demographics.

\begin{tabular}{|c|c|c|c|c|}
\hline Prices Used in Survey & Asthma Study & Dyslipidemia Study & Diabetes Study & Total \\
\hline Prices Used in Survey & $\$ 15,40$, and 80 & $\$ 15$ and 60 & $\$ 15,40$, and 80 & -- \\
\hline $\mathrm{N}$ & $52^{\mathrm{a}}$ & $81^{b}$ & $164^{\mathrm{b}}$ & 297 \\
\hline Mean Age (sd) & $50(15.5)^{c}$ & $61.1(10.8)$ & $58.6(13.3)$ & $56.4(14.3)$ \\
\hline \% Female & $82 \%{ }^{d}$ & $64 \%$ & $65.9 \%$ & $70.6 \%$ \\
\hline Mean Years Education (sd) & $11.5(3.3)$ & $12.9(2.7) \mathrm{C}$ & $11.6(3.3)$ & $11.9(3.1)$ \\
\hline Mean Income, US Dollars (sd) ${ }^{\mathrm{d}}$ & $\$ 16,214^{d}$ & $\$ 30,965$ & $\$ 31,173$ & $\$ 26,459$ \\
\hline$(22,818)$ & $(27,776)$ & $(28,970)$ & $(26,589)$ & \\
\hline Ethnicity (\% white) & $87.9 \%{ }^{\mathrm{d}}$ & $94.7 \%$ & $91 \%$ & $90.8 \%$ \\
\hline
\end{tabular}

${ }^{a}$ Number of subjects declining the hypothetical offer to purchase the service; motivation questions were not asked of those declining the real offer to purchase the service; ${ }^{b}$ Number of subjects declining the hypothetical or real offer to purchase the service; ${ }^{c} \mathrm{p}<0.05$; ${ }^{\mathrm{d}}$ For household income the subject could either fill in the exact amount or mark one of the following categories: <\$5000, \$5000 - 10000, \$10001 - $20000, \$ 20001-30000$, \$30001 - 50000, $\$ 50001$ - 100000, $\$ 100001$ - 150000, > \$150000. A continuous income measure was constructed by setting the income for each subject to the midpoint of the interval ( $\$ 175,000$ was used as the midpoint for the highest income category).

Table 2. Reasons for not purchasing disease management services ${ }^{\mathrm{a}}$. Number followed by percentage.

\begin{tabular}{|c|c|c|c|c|}
\hline & Asthma Study & Dyslipidemia Study & Diabetes Study & Total \\
\hline Financial & $30(50)$ & $20(23.5)$ & $69(40.1)$ & $119(37.5)$ \\
\hline Already Receive Service & $5(8.3)$ & $44(51.8)$ & $47(27.3)$ & $96(30.3)$ \\
\hline Don't Need the Program & $14(23.3)$ & $13(15.3)$ & $28(16.3)$ & 55 (17.4) \\
\hline Transportation/Time & $4(6.7)$ & $1(1.2)$ & $15(8.7)$ & $20(6.3)$ \\
\hline Miscellaneous & $2(3.3)$ & $6(7.1)$ & $13(7.6)$ & $21(6.6)$ \\
\hline No Response & $5(8.3)$ & $1(1.2)$ & 0 & $6(1.9)$ \\
\hline
\end{tabular}

${ }^{\mathrm{a}}$ Some respondents included more than one reason.

reason to decline purchase overall was the perception that similar services were already being provided by other healthcare professionals; although this was not the case for the asthma program, where lack of need for the service was the second most common reason to decline the service.

Some pharmacists believe that disease management services are not routinely provided by other healthcare professionals, and that consumer/patients would value and gladly purchase such services if offered by pharmacists. Our findings demonstrate a potential disconnect between consumer/patient and pharmacist perceptions of these services. This disconnect has recently been described by Wang and Hong who found that pharmacists believe $\$ 60$ is acceptable compensation for a 30-minute MTM session, an amount that exceeds what patients and third-party payers are willing to pay [25].

Our review of the data indicates that consumer/patients' motivation for not purchasing pharmacist-provided services varies based on the type of service being offered. Financial constraints were most commonly cited as rationale for declining the offer to purchase diabetes and asthma services. Asthma and diabetes have been shown to be more prevalent in lower socioeconomic populations, which may explain why individuals with these diseases cited lack of financial resources most often [26]-[29]; although, we did not explicitly evaluate this association here. Consumer/patients with dyslipidemia most often indicated that they declined the offer to purchase the service because they perceived similar services were already being provided by other healthcare professionals. Dyslipidemia is a "silent disease" in which self-management techniques are generally limited to lifestyle changes and medication adherence, thus, the potential role that pharmacists could play in the management of this disease may not be recognized.

The response of "no need" represents $15 \%$ - 23\% of subjects who declined to purchase the disease management services. Responses categorized as "no need" may indicate that consumer/patients perceive little risk from their disease or that they perceive their current level of disease control to be adequate; thus, they were unable to justify purchase of the disease management service. Another potential reason why patients may have indicated "no need" is that they may not recognize the role a pharmacist-provided disease management service may play 
in the control of their disease. Patients do not necessarily expect to receive disease management services when they interact with the pharmacist; rather they tend to expect the pharmacist to fill their prescriptions in a timely manner and provide basic medication information [30]. This perception has recently been by documented by Smith and colleagues who report that both patients and physicians have difficulty envisioning pharmacists in non-dispensing roles [31]. Patient education regarding the pharmacist's role in decreasing medication-related problems and improving health outcomes is needed to enhance the patient's perception of pharmacists as a healthcare provider.

This secondary analysis of previously collected data contains several limitations. First, consumer/patients in the willingness to pay studies provided their rationale for not purchasing the pharmacist-provided service in their own words, which were subsequently relegated into one of five categories by a panel of individuals. All members of the panel had a pharmacy background; thus it is possible that the categorization process may have been biased. Additionally, all responses were elicited from patrons of independent community pharmacies located throughout Kentucky. Different responses may have been obtained had patrons of chain pharmacies been included in the sample. The sociodemographic characteristics of the sample are similar to what one would expect within the state of Kentucky; however, they do not represent the population overall within the US. An additional potential limitation is that some of the data were compiled from consumer/patients who were hypothetically offered the opportunity to purchase the pharmacist-provided disease management service. Thus, it is possible that they may have offered a "hypothetical" motivation for why they declined the service (i.e., they may have responded differently to the motivation question had they believed the offer to purchase was, in fact, a real offer to purchase the pharmacist-provided service).

\section{Conclusions}

As the profession continues its efforts to shift the paradigm of practice from traditional dispensing to that of care provider, there is much to consider. The development and implementation of a pharmacist-provided disease management program requires significant financial resources and some studies have demonstrated that consumer demand for these services is lacking [21]-[23]. Furthermore, other research documents the disconnection between third-party payment for non-dispensing services and the amount pharmacists consider acceptable compensation [25]. Currently, payment from third-parties such as Medicare and Medicaid is inconsistent. The provision of MTM services as part of the 2003 Medicare Modernization Act has done little to ensure the consistency of reimbursement for other pharmacist-provided patient care services. Without adequate reimbursement, community pharmacists are limited in their capacity to generate substantial income from MTM and disease management services as alternative revenue sources.

The profession would be wise to carefully consider the non-financial reasons provided by consumers who are not interested in purchasing pharmacist-provided services. It is not just the cost of the service that drives the lack of consumer demand; the belief that pharmacist-provided disease management services are duplicative, or are not needed, are significant barriers to overcome. Intensive education and marketing campaigns are needed to sway consumer opinion on the value of pharmacist-provided services.

\section{Acknowledgements}

This work was funded by a grant from the NCPA Foundation. The assistance of Charity Price and Virginia Engoglia is gratefully acknowledged.

\section{References}

[1] Carroll, N.V., Miederhoff, P.A. and Waters, L.W. (1996) Profitability, Third-Party Reimbursement, and Access to Community Pharmacies. Clinical Therapeutics, 118, 703-715. http://dx.doi.org/10.1016/S0149-2918(96)80221-9

[2] Anon (2005) Trend of the Month: Pharmacy Reimbursement Continues to Drop. Drug Benefit Trends, 17, 8.

[3] NACDS Statement on Medicaid Prescription Drugs: Examining Options for Payment Reform. Presented to the Hearing of the House Energy and Commerce Committee Subcommittee on Health, 2005.

[4] Willink, D.P. and Isetts, B.J. (2005) Becoming “Indispensable”: Developing Innovative Community Pharmacy Practices. Journal of the American Pharmacists Association, 45, 376-389. http://dx.doi.org/10.1331/1544345054003859

[5] Doucette, W.R., Kreling, D.H., Schommer, J.C., Gaither, C.A., Mott, D.A. and Pedersen, C.A. (2006) Evaluation of 
Community Pharmacy Service Mix: Evidence from the 2004 National Pharmacist Workforce Study. Journal of the American Pharmacists Association, 46, 348-355. http://dx.doi.org/10.1331/154434506777069651

[6] Giberson, S., Yoder, S. and Lee, M.P. (2011) Improving Patient and Health System Outcomes through Advanced Pharmacy Practice. A Report to the U.S. Surgeon General. Office of the Chief Pharmacist, U.S. Public Health Service.

[7] Ganther, J.M. (2002) Third-Party Reimbursement for Pharmacist Services: Why Has It Been So Difficult to Obtain and Is It Really the Answer for Pharmacy. Journal of the American Pharmacists Association, 42, 875-879. http://dx.doi.org/10.1331/108658002762063736

[8] Beatty, S.J., Rodis, J.L., Bellebaum, K.L. and Mehta, B.H. (2006) Community and Ambulatory Pharmacy: Evaluation of Patient Care Services and Billing Patterns before Implementation of Medicare Part D. Journal of the American Pharmacists Association, 46, 707-714. http://dx.doi.org/10.1331/1544-3191.46.6.707.Beatty

[9] Beatty, S.J., McCormick, K.M., Beale, D.J., Bruggeman, A.M., Rodis, J.L., Mehta, B.H. and Bennett, M.S. (2012) Current Trends in Outpatient Pharmacy Services and Billing. Journal of the American Pharmacists Association, 52, 154-160. http://dx.doi.org/10.1331/JAPhA.2012.11213

[10] Bernsten, C., Andersson, K., Gariepy, Y. and Simoens, S. (2010) A Comparative Analysis of Remuneration Models for Pharmaceutical Professional Services. Health Policy, 95, 1-9. http://dx.doi.org/10.1016/j.healthpol.2009.11.008

[11] Skelton, J.B. (2011) Pharmacist-Provided Immunization Compensation and Recognition: White Paper Summarizing APhA/AMCP Stakeholder Meeting. Journal of the American Pharmacists Association, 51, 704-712. http://dx.doi.org/10.1331/JAPhA.2011.11544

[12] Federal Register/Vol. 70, No. 18/Friday, January 28, 2005/Rules and Regulations.

[13] Snella, K.A., Trewyn, R.R., Hansen, L.B., et al. (2004) Pharmacist Compensation for Cognitive Services: Focus on the Physician Office and Community Pharmacy. Pharmacotherapy, 24, 372-388. http://dx.doi.org/10.1592/phco.24.4.372.33179

[14] Schafermeyer, K. (1999) The Impact of Managed Care on Pharmacy Practice. In: Navarro, R., Ed., Managed Care Pharmacy Practice, Aspen Publishers, Gaithersburg, 451-473.

[15] Bluml, B.M., McKenney, J.M. and Cziraky, M.J. (2000) Pharmaceutical Care Services and Results in Project Impact: Hyperlipidemia. Journal of the American Pharmacists Association, 40, 157-165.

[16] Bennett, M.S., Blank, D., Bopp, J., et al. (2000) Strategies to improve compensation for pharmaceutical care services. Journal of the American Pharmacists Association, 40, 747-755, 870-872.

[17] Johannesson, M., Johansson, P.-O. and Jönsson, B. (1992) Economic Evaluation of Drug Therapy: A Review of the Contingent Valuation Method. PharmacoEconomics, 1, 325-337. http://dx.doi.org/10.2165/00019053-199201050-00004

[18] Woelfel, J.A., Carr-Lopez, S.M., Delos Santos, M., Bui, A., Patel, R.A., Walberg, M.P. and Galal, S.M. (2014) Assessing Medicare Beneficiaries' Willingness-to-Pay for Medication Therapy Management Services. The Consultant Pharmacist, 29, 104-109. http://dx.doi.org/10.4140/TCP.n.2014.104

[19] Schuh, M.J. and Droege, M. (2008) Cognitive Services Provided by Pharmacists: Is the Public Willing to Pay for Them? The Consultant Pharmacist, 23, 223-230. http://dx.doi.org/10.4140/TCP.n.2008.223

[20] Friedrich, M., Zgarrick, D., Masood, A. and Montuoro, J. (2010) Patients’ Needs and Interests in a Self-Pay Medication Therapy Management Service. Journal of the American Pharmacists Association, 50, 72-77. http://dx.doi.org/10.1331/JAPhA.2010.08126

[21] Blumenschein, K., Johannesson, M. and Yokoyama, K. (2001) Hypothetical vs. Real Willingness to Pay in the Health Sector: Results from a Field Experiment. Journal of Health Economics, 20, 441-457. http://dx.doi.org/10.1016/S0167-6296(01)00075-3

[22] Blomquist, G.C., Blumenschein, K. and Johannesson, M. (2009) Eliciting Willingness to Pay without Bias Using Follow-Up Certainty Statements: Comparison between Probably/Definitely and a 10-Point Certainty Scale. Environmental and Resource Economics, 43, 473-502. http://dx.doi.org/10.1007/s10640-008-9242-8

[23] Blumenschein, K., Blomquist, G.C., Johannesson, M., Horn, N. and Freeman, P. (2008) Eliciting Willingness to Pay without Bias: Evidence from a Field Experiment. The Economic Journal, 118, 114-137.

[24] Carson, R.T. (2000) Contingent Valuation: A User’s Guide. Environmental Science and Technology, 34, $1413-1418$. http://dx.doi.org/10.1021/es990728j

[25] Wang, J. and Hong, S.H. (2012) Contingent Valuation and Pharmacists’ Acceptable Levels of Compensation for Medication Therapy Management Services. Research in Social \& Administrative Pharmacy. http://www.ncbi.nlm.nih.gov/pmc/articles/PMC3445666/pdf/nihms365450.pdf

[26] Global Initiative for Asthma (GINA) (2004) Global Strategy for Asthma Management and Prevention. National Institute of Health, Bethesda, Publication No. 02-3659. 
[27] Basagaa, X., Sunyer, J., Kogevinas, M., et al. (2004) Socioeconomic Status and Asthma Prevalence in Young Adults. American Journal of Epidemiology, 160, 178-188. http://dx.doi.org/10.1093/aje/kwh186

[28] Robbins, J.M., Vaccarino, V., Zhang, H., et al. (2001) Socioeconomic Status and Type 2 Diabetes in African American and Non-Hispanic White Women and Men: Evidence from the Third National Health and Nutrition Examination Survey. American Journal of Public Health, 91, 76-83. http://dx.doi.org/10.2105/AJPH.91.1.76

[29] Connolly, V., Unwin, N., Sherriff, P., et al. (2000) Diabetes Prevalence and Socioeconomic Status: A Population Based Study Showing Increased Prevalence of Type 2 Diabetes Mellitus in Deprived Areas. Journal of Epidemiology \& Community Health, 54, 173-177. http://dx.doi.org/10.1136/jech.54.3.173

[30] Kradjan, W.A., Schulz, R., Christensen, D.B., et al. (1999) Patients’ Perceived Benefit from and Satisfaction with Asthma-Related Pharmacy Services. Journal of the American Pharmacists Association, 39, 658-666.

[31] Smith, M., Cannon-Breland, M.L. and Spiggle, S. (2013) Consumer, Physician, and Payer Perspectives on Primary Care Medication Management Services with a Shared Resource Pharmacist Network. Research in Social \& Administrative Pharmacy. 